\title{
Major hospital transformations: An integrative review and implications for nursing
}

\author{
Julie Fréchette*1, Mélanie Lavoie-Tremblay ${ }^{1}$, Monique Aubry ${ }^{2}$, Kelley Kilpatrick ${ }^{1}$, Vasiliki Bitzas ${ }^{1,3}$ \\ ${ }^{1}$ McGill University Ingram School of Nursing, Montreal, QC, Canada \\ ${ }^{2}$ Department of Management and Technology, Université du Québec à Montréal, Montreal, QC, Canada \\ ${ }^{3}$ Quebec Integrated University Centre for Health and Social Services of Western Central Montreal Island, Montreal, Canada
}

Received: February 11, 2020

DOI: $10.5430 /$ jnep.v10n7p46
Accepted: April 7, 2020

URL: https://doi.org/10.5430/jnep.v10n7p46

\begin{abstract}
Major hospital transformations, hospital projects that combine construction and quality improvement dimensions, are booming around the globe. These costly endeavours have the potential to revolutionize healthcare, yet no known review explores this phenomenon, undermining accessibility of knowledge for healthcare leaders. In order to provide guidance on healthcare project management and on future research avenues, this article aims to synthesize empirical knowledge concerning major hospital transformations and their implications for nursing. An integrative review of the literature using the systematic approach described by Whittemore and Knafl was selected. As major hospital transformations represent a new area of research, the review includes 13 articles out of 116 retrieved for screening. The search strategy included the following electronic databases: CINAHL, MEDLINE, and Business Source Complete. Three main themes emerged from the data: the challenging context of major hospital transformations, the project management office as a key to successful healthcare change, and the absence of certain stakeholders' voices. Major hospital transformations are important to study holistically as multi-change initiatives cannot be understood through investigating individual changes alone. Healthcare leaders are called to reflect on their governance structures during organisational transformations, as well as on the inclusion and exclusion of certain stakeholders who are essential to making sustainable change.
\end{abstract}

Key Words: Major hospital transformation, Healthcare change, Project management office, Integrative literature review

\section{INTRODUCTION}

A construction boom in healthcare is currently felt around the world, with massive public and private financial investment in infrastructure renewal. ${ }^{[1-3]}$ The major hospital transformations that result from these investments extend "well beyond the dimensions of a typical brick-and-mortar project... [as their] main concern is harmonization and optimization of clinical and administrative practices". ${ }^{[4]}$ A major hospital transformation project is defined as the construction of new physical environments in a hospital setting, combined with multiple improvement projects. ${ }^{[1,5]}$ Although the most visi- ble changes in these transformations are the new buildings or units, multiple projects are occurring simultaneously in different spheres of hospital functioning, including and not limited to technology, clinical practice, administrative processes, team dynamics, organisational culture, etc. ${ }^{[4]}$ Tucker, Hendy, et al. ${ }^{[6]}$ highlight the importance of research into the interconnectedness between healthcare infrastructure and work redesign, as the junction between these different projects creates unique challenges. The changes that result from these major transformation projects are complex and multidisciplinary. ${ }^{[3,7]}$

*Correspondence: Julie Fréchette; Email: julie.frechette2@mail.mcgill.ca; Address: McGill University Ingram School of Nursing, 680 Sherbrooke West, Suite 1800, Montreal, QC, Canada. 
Moreover, the complexity inherent to these projects is amplified by the complexity of the healthcare system itself. ${ }^{[8]}$ Indeed, healthcare is marked by a variety of stakeholders (administrators, nurses, patients, etc.) in relationships characterized by power differentials and pluralistic perspectives and values (patient care, cost containment, etc.). ${ }^{[9,10]}$ Tensions are inherent in a system like this, or a professional bureaucracy as coined by Mintzberg, ${ }^{[11]}$ since administrators' need for control will inevitably clash with clinicians' need for autonomy. ${ }^{[11]}$ Rouse and Serban ${ }^{[12]}$ suggest that the healthcare system is a complex adaptive system, meaning that the intricate webs of intelligent actors within this system have a high capacity to change and self-organise. The healthcare system makes for a very rich setting to study project management in all its complexity, especially in the context of major hospital transformations. To date, no known review has explored the phenomenon of major hospital transformations. In order to provide guidance for healthcare leaders on project management and future research avenues, this integrative review aims to synthesize empirical knowledge concerning major hospital transformations and the role occupied by nurses in these complex changes.

\section{METHODS}

An integrative review of major hospital transformations was conducted using the method described by Whittemore and Knaf ${ }^{[13]}$ and further explicated by Carvalho, Silva, et al. ${ }^{[14]}$ This type of knowledge synthesis is composed of five steps: problem identification, literature search, data evaluation, data analysis and presentation. ${ }^{[13]}$ An integrative review is ideal to "capture the depth and breadth of the topic" and in this way, identify gaps in knowledge that require further research. ${ }^{[15]}$

\subsection{Problem identification}

The topic of a major hospital transformation is defined as a project with both construction and quality improvement dimensions in a hospital setting. ${ }^{[1,4,5]}$ Therefore, the inclusion criteria are as follow: 1) Empirical studies using quantitative, qualitative or mixed methods designs, as all these types of studies can enrich understanding of the topic, ${ }^{[16]}$ 2) Hospital setting including hospital, acute, secondary and tertiary care facilities, 3) Change at the organisational level that includes both construction and other projects, and 4) English and French.

\subsection{Literature search}

Since major hospital transformations constitute an emerging area of research, the works of two experts in healthcare project management, Dr. Lavoie-Tremblay and Dr. Aubry, were first consulted to identify relevant medical subject head- ing (MeSH) terms and keywords. The search strategy included Hospital Design and Construction, Facility Design and Construction, and Interior Design and Furnishings as main headings, as well as the following keywords: evidencebased design, transformation, hospital and construction. A healthcare librarian validated the search strategy and the following types of information sources:

- Electronic Databases. CINAHL Plus with Full Text, Ovid MEDLINE@ and In-Process \& Other NonIndexed Citations 1996-, and Business Source Complete (1886-present).

- Citation Tracking. Forward reference searching and backward reference searching were conducted through ISI Web of Science (when the article was indexed) or manual backward reference searching for other articles.

The initial search yielded 116 articles (see Figure 1); these were retrieved into EndNote and the duplicates removed using the method described by Bramer, Giustini, et al. ${ }^{[17]}$

\subsection{Data evaluation, analysis and presentation}

Data were extracted concerning the methodology, the participants, the setting, and the main results in relation to major hospital transformations (see Table 1). The quality of the selected studies was evaluated using the Mixed Methods Appraisal Tool (MMAT). ${ }^{[18-20]}$ The MMAT was selected because it is a reliable tool which allows the evaluation of the methodological quality of qualitative, quantitative and mixed methods studies. ${ }^{[18-20]}$ Quality scores are presented through four descriptors (low quality-high quality; $\left.*_{-} * * * *\right) .{ }^{[20]}$ Thematic analysis, according to the method proposed by Miles and Huberman ${ }^{[21]}$ and further described by Langley, ${ }^{[22]}$ was chosen to synthesize common and divergent themes. The key findings from the included studies were synthesized (data reduction step) and presented in a tabular form (See Table 1; data display step). ${ }^{[21,22]}$ Themes were generated inductively through a back-and-forth movement from the synthesized data to emerging themes, until the themes did not significantly change (conclusion drawing and verification step). ${ }^{[21,22]}$

\section{RESULTS}

Research about major hospital transformations is emergent (less than ten years) and conducted mostly in North America (Canada \& USA $=12 / 13$ and UK $=1 / 13$ ). Case study methodology $(n=11 / 13)$ is predominant. Three main themes emerged from the data: the context of major hospital transformations, the project management office (PMO), and the stakeholders. 


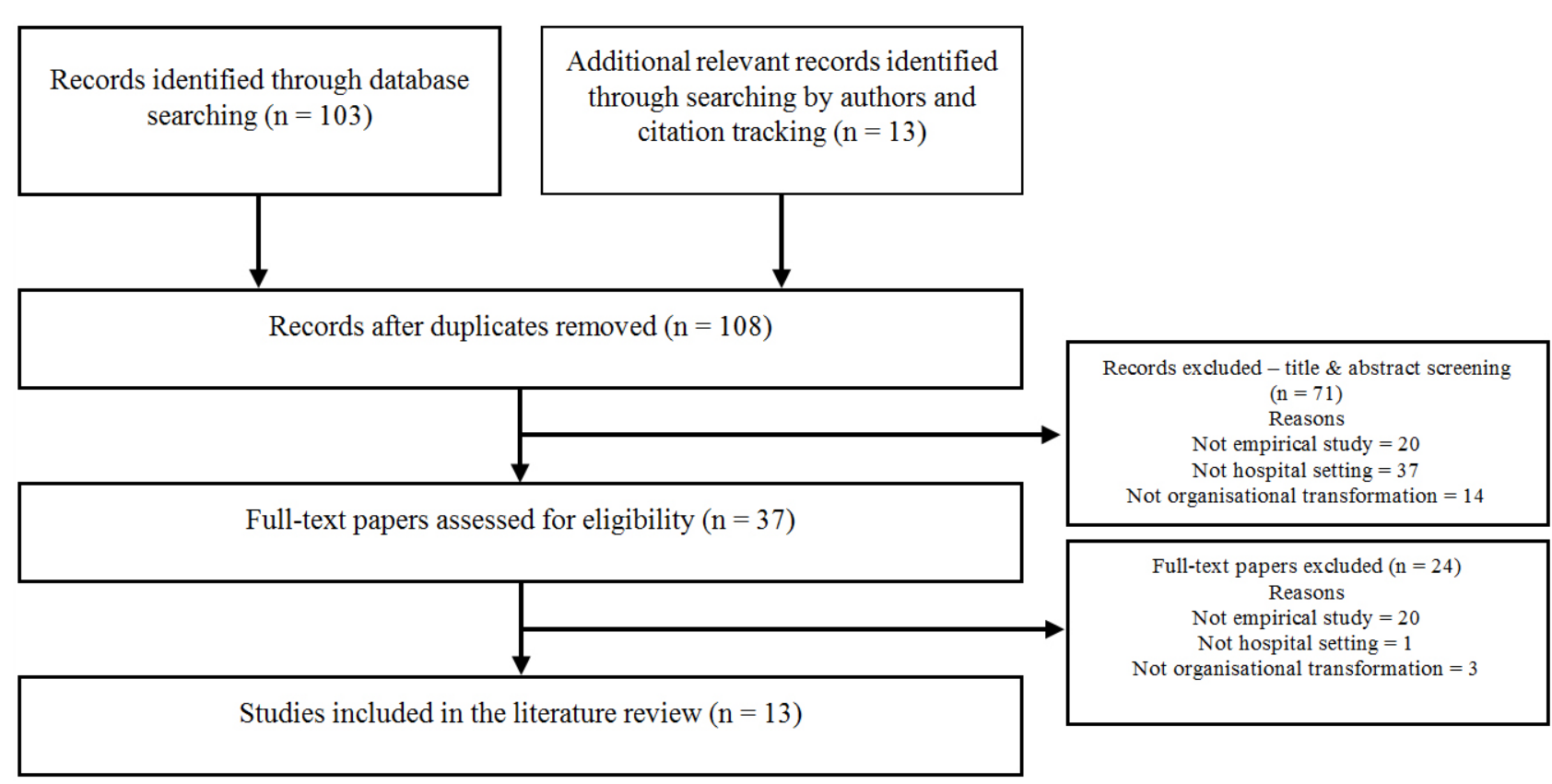

Figure 1. PRISMA Flow diagram based on the review of major hospital transformations

3.1 The challenging context of major hospital transformations

The construction of new infrastructure presents, on the one hand, great opportunities to enhance patient care, and on the other hand, numerous challenges for the changing organisation. ${ }^{[1,6]}$ Difficulties related to lack of communication, resistance to change and limited resources are reported, ${ }^{[1]}$ as well as challenges in enabling change within a complex organisation, where multiple hierarchies and care cultures coexist. ${ }^{[4]}$ Richer, Dawes, et al. ${ }^{[23]}$ report that information needs are great and diversified during this transformation period while Tucker, Hendy, et al. ${ }^{[6]}$ highlight the cognitive overload linked with redesigning work practices. Healthcare leaders and teams must surmount these challenges in order to successfully transform their organisation, yet besides the project management office, little is known concerning facilitating factors.

\subsection{The project management office as a key to successful change}

A considerable portion of the scarce literature on hospital transformation projects $(n=8 / 13)$ relates to PMOs, also referred to as Transition Support Offices (TSOs). PMOs are defined as "an organizational structure that standardizes the project-related governance processes and facilitates the sharing of resources, methodologies, tools, and techniques". ${ }^{[24]}$ More concretely, a healthcare PMO is a parallel administrative structure, temporarily established during the transformation to provide project management expertise, support evidence-based practice, process review, and evaluation. ${ }^{[1,25]}$ Another common function associated with healthcare PMOs is prioritization of large volumes of projects. ${ }^{[25,26]}$ Through these roles, PMOs have been shown to be effective in supporting organisations undergoing major transformations. ${ }^{[1,3,25-27]}$

\subsection{The absence of stakeholders' voices}

In major hospital transformations, a variety of stakeholders (PMO members, managers, clinicians, patients, etc.), with pluralistic viewpoints, are involved in and/or impacted by the organisational change. ${ }^{[4]}$

\subsubsection{PMO teams}

PMO team members facilitate major hospital transformations through providing project management support, energizing teams and giving them a sense of direction, facilitating discussions and providing information needed for decisionmaking. ${ }^{[1,3]}$ Recognized for their expertise, credibility and neutrality, PMO team members are pivotal to PMO performance. ${ }^{[1]}$ In the case of one healthcare organisation in Quebec, Canada, nurses were integral to the PMO through their roles as director, knowledge brokers, evidence-based practice experts, quality and performance evaluation experts, and students. ${ }^{[1]}$ More specifically, the role of knowledge broker was effective in supporting organisations through information overload. $^{[28]}$

\subsubsection{Point-of-care nurses}

Whereas researchers in this field recognize point-of-care nurses as key players in healthcare change, ${ }^{[1,26,29]}$ no known study has addressed their specific disciplinary perspective 
in hospital transformations. Current research has mostly solicited managers, PMO members and project team members as participants, and three research studies investigated employees in general. Bareil, Savoie, et al. ${ }^{[30]}$ showed that the discomfort felt by employees is actually more contingent on characteristics of the change itself than individual disposition. In addition, Tucker, Hendy, et al. ${ }^{[6]}$ report that employees need to understand the reasons for design decisions to enable work redesign to occur in practice. Similarly, Slosberg, Nejati et al. ${ }^{[29]}$ showed "a strong relationship between employee engagement and their level of preparedness to move, readiness to adapt, and satisfaction [with the new building]". [29] These results highlight the importance of healthcare leaders stimulating employee engagement, including that of nurses, in order to facilitate the transformation and staff adaptation to change. Unfortunately, these articles fall short in offering strategies to support employee engagement, which makes it less practicable in the hospital setting.

\section{Discussion}

In summary, a small volume of research $(n=13)$ has explored the context of major hospital transformations, as well as the role and performance of PMOs in this context. Current research into major hospital transformations has mostly solicited managers, PMO members, and project team members as participants.

Research to date shows that PMOs are important organisational governance structures to consider for successful hospital transformation. Firstly, PMOs attenuate the impacts of challenges associated with the major hospital transformation context. ${ }^{[4,27]}$ This effect is particularly interesting since the transforming organisation faces numerous challenges (i.e., high information needs, competing priorities, etc.) and the PMO can potentially alleviate some of these burdens. Secondly, major hospital transformation studies report that PMOs support the integration of diverse projects. ${ }^{[7,26,27]}$ This function is crucial in a transformational context, as multiple interdisciplinary projects are competing in a complex web of power dynamics. ${ }^{[9-11]}$ As highlighted in the studies by Lavoie-Tremblay, et al. ${ }^{[1,3]}$ the non-partisan PMO team provides a neutral ground on which to prioritize projects with the big picture in mind versus the disciplinary/departmental tug of war. Research therefore suggests that healthcare administrators should consider a PMO when reflecting about what governance structure to implement during a major organisational transformation. More research concerning healthcare PMOs is needed to identify what PMO roles are essential in supporting organisational change, and to measure their impact on project management effectiveness.

In order to contextualize the research findings about major Published by Sciedu Press hospital transformations, it must be noted that much research, both in healthcare and management, have investigated circumscribed change initiatives or projects. For example, a considerable volume of literature, falling under the umbrella of 1) implementation science, focuses on the integration of healthcare evidence-based interventions, ${ }^{[31]}$ and 2) evidencebased design, targets infrastructure dimensions. ${ }^{[32]}$ What differentiates these from major hospital transformation research is that a transformation involves multiple layers of projects, intricately linked together in a complex web involving all organisational levels. Each project studied individually does not add up to the big picture, as it misses the junctions between these changes, and the complexity that makes major transformations unique. ${ }^{[6]}$ Despite this difference, the importance of people at the heart of change is a key lesson of implementation research in healthcare settings ${ }^{[31]}$ that also applies to organisational transformations and to the domain of change management. ${ }^{[33]}$

\subsection{The absence of nurses' voice}

Unfortunately, the voices of nurses and patients, who are at the heart of major hospital transformations, are mostly absent from the literature to date. A nursing perspective cannot be overlooked for two main reasons: nurses are key change agents in healthcare, and along with patients, are amongst those most impacted by change. ${ }^{[34-36]}$

Firstly, by being recognized experts in leading change, and by having close ties with patients and families, nurses power a high number of projects. Nurses are essential to successful implementation of healthcare changes that lead to improved patient care $;{ }^{[34,35,37]}$ point-of-care nurses essentially make or break quality improvement initiatives. Anecdotally, it is well recognized that nurses who resist change will find creative workarounds and that the anticipated benefits of the initial project will never materialize without nurses' adherence. It is therefore recommended to include nurses as full partners in healthcare transformations, in order to lead change successfully. ${ }^{[34]}$ Point-of-care nurses' perspective about major hospital transformations will provide insight into ways to engage nurses as full partners in projects, ultimately leading to lasting changes in everyday care.

Secondly, since nurses hold such a central role in care and represent the largest healthcare profession, they are often impacted by project work. ${ }^{[3]}$ Clinicians often engage in multiple projects concurrently ${ }^{[38]}$ and juggle their normal jobs with the added workload of projects, while facing unclear expectations as to how to manage their priorities. ${ }^{[39]}$ Exacerbating these pressures is the excessive number of changes experienced in the healthcare system. ${ }^{[40]}$ In addition, projects and organisational transformations can have a detrimental impact 
on nurses' health. A recent study showed that hospital nurses "who experienced more frequent structural changes" had a higher probability of absence for long-term sickness. ${ }^{[41]}$ Nurses undergoing organisational change and restructuring experience greater stress, ${ }^{[42-44]}$ and higher psychological distress. ${ }^{[45,46]}$ Statistically, organisational change stressors also decrease nurses' job satisfaction. ${ }^{[44]}$ Leaders of major healthcare change must strike a delicate balance to keep nurses healthy. Research concerning point-of-care nurses' perspective of major hospital transformations will provide clues to achieving that balance, while leveraging nurses' insight to actualize project success.

\subsection{Methodological inquiry}

Case studies predominate in this integrative literature review, which is consistent with the embryonic state of research concerning major hospital transformations. This methodology offers a rich descriptive understanding of transformations and favors the identification of processes over time (i.e., the trajectory of PMO designs over time in Aubry and LavoieTremblay ${ }^{[26]}$. Since there is such a pressing need to explore point-of-care nurses' perspectives, a case study methodology is not most suited to allow for in-depth exploration of the phenomenon's meaning for those concerned. Interpretive phenomenological research provides a great opportunity to uncover not only the descriptive experiences of a phenomenon, but the meanings that these hold for individuals, their lived experiences of the phenomenon. Nurses' experiences with projects shows how these can be transformational for them, ${ }^{[47]}$ and supports the need for more in-depth research into their lived experience of projects and environmental changes. Future research should focus on point-of-care nurses' lived experience of major hospital transformations in order to enrich understanding of the meanings transformations hold for nurses; the results from this research avenue would support healthcare leaders in engaging point-of-care nurses in transformations, and mobilize nurses to contribute their expertise towards improved patient care.

\subsection{Limitations}

This integrative review offers a targeted perspective on the phenomenon of major hospital transformations. Studies that investigate healthcare construction projects (i.e., evidence- based design, architecture, etc.) and quality improvement projects (i.e., clinical interventions, implementation of information technology systems, etc.) separately were excluded, as the focus of interest was the complexity inherent to integrating these interdisciplinary projects together. The literature on the topic is still young (articles have been published for the past 10 years), with a large portion of the scholarly work using exploratory methodologies. This literature review is timely, as this emergent field of study needs a vision for future research. Despite the generally high quality of the articles retrieved, most studies took place in a North American context with a limited number of different cases investigated.

\section{Conclusion}

This integrative review contributes to the current state of knowledge in healthcare management by synthesizing the empirical knowledge concerning major hospital transformations and the role occupied by nurses in these complex changes. Little is known concerning point-of-care nurses' and patients' perspectives of major hospital transformations. This integrative review provides guidance for healthcare leaders, on healthcare project management and on future research avenues. More research, from diverse professions, traditions and methodologies, would be needed to further understand the perspectives of major hospital transformation users, especially point-of-care nurses and patients. Ultimately, more knowledge concerning nurses' and patients' perspectives would facilitate the creation of hospital environments more conducive to quality health care.

\section{ACKNOWLEDGEMENTS}

The first author would like to thank the Fonds de recherche du Québec - Santé (FRQ-S), the Quebec Network on Nursing Intervention Research (RRISIQ), the Quebec Ministry of Education, the Institut universitaire en santé mentale de Montréal - Research Center, Mitacs, and McGill University for their doctoral financial support.

\section{CONFlicts of Interest Disclosure}

The authors declare no potential conflicts of interest with respect to the research, authorship, and/or publication of this article.

\section{REFERENCES}

[1] Lavoie-Tremblay M, Richer MC, Marchionni C, et al. Implementation of Evidence-Based Practices in the Context of a Redevelopment Project in a Canadian Healthcare Organization. Journal of Nursing Scholarship. 2012; 44(4): 418-27. PMid:23121763 https://doi.org/10.1111/j.1547-5069.2012.01480.x

[2] France D, Throop P, Joers B, et al. Adapting to family-centered hospital design: changes in providers' attitudes over a two-year period. Health Environments Research \& Design Journal. 2009; 3(1): 79-96. PMid:21165881 https://doi.org/10.1177/19375867090030 
0107

[3] Lavoie-Tremblay M, Aubry M, Cyr G, et al. Innovation in health service management: Adoption of project management offices to support major health care transformation. Journal of Nursing Management. 2017; 25(8): 657-65. PMid:28891171 https://doi.or $\mathrm{g} / 10.1111 /$ jonm. 12505

[4] Aubry M, Richer MC, Lavoie-Tremblay M, et al. Pluralism in PMO performance: The case of a PMO dedicated to a major organizational transformation. Project Management Journal. 2011; 42(6): 60-77. https://doi.org/10.1002/pmj. 20269

[5] Richer MC, Marchionni C, Lavoie-Tremblay M, et al. The project management office: transforming healthcare in the context of a hospital redevelopment project. Healthcare Management Forum. 2013; 26(3): 150-6. PMid:24409583 https://doi.org/10.1016/j.hc $\mathrm{mf} .2013 .05 .001$

[6] Tucker DA, Hendy J, Barlow J. When infrastructure transition and work practice redesign collide. Journal of Organizational Change Management. 2014; 27(6): 955-72. https://doi.org/10.1108/ JOCM-09-2013-0173

[7] Aubry M, Richer MC, Lavoie-Tremblay M. Governance performance in complex environment: The case of a major transformation in a university hospital. International Journal of Project Management. 2014; 32(8): 1333-45. https://doi.org/10.1016/j.ijproman. 201 3.07 .008

[8] Mintzberg H. Managing the Myths of Health Care : Bridging the Separations between Care, Cure, Control, and Community. Oakland, CA: Berrett-Koehler Publishers; 2017. https ://doi .org/10.100 7/978-3-319-53600-2_1

[9] Denis JL, Lamothe L, Langley A. The dynamics of collective leadership and strategic change in pluralistic organizations. Academy of Management Journal. 2001; 44(4): 809-37. https://doi .org/10 $.2307 / 3069417$

[10] Denis JL, Dompierre G, Langley A, et al. Escalating indecision: Between reification and strategic ambiguity. Organization Science. 2011; 22(1): 225-44. https://doi.org/10.1287/orsc.1090.0501

[11] Mintzberg H. The structuring of organizations : a synthesis of the research. Englewood Cliffs, NJ: Prentice-Hall; 1979.

[12] Rouse WB, Serban N. Understanding and managing the complexity of healthcare. Cambridge, MA: The MIT Press; 2014

[13] Whittemore R, Knafl K. The integrative review: updated methodology. Journal of Advanced Nursing. 2005; 52(5): 546-53. PMid:16268861 https://doi.org/10.1111/j.1365-2648.20 $05.03621 . x$

[14] Carvalho Rd, Silva MDd, Souza MTd. Integrative review: what is it? How to do it? eins Einstein (São Paulo). 2010; 8(1): 102-6. PMid:26761761 https://doi.org/10.1590/s1679-450 82010rw1134

[15] Kastner M, Antony J, Soobiah C, et al. Conceptual recommendations for selecting the most appropriate knowledge synthesis method to answer research questions related to complex evidence. Journal of Clinical Epidemiology. 2016; 73: 43-9. PMid:26912124 https://doi.org/10.1016/j.jclinepi.2015.11.022

[16] Pluye P, Vedel I, Hong QN. Module 1: Part 2 - Reviews of empirical studies. In: Medicine DoF, editor. Montreal, Canada: McGill University; 2017.

[17] Bramer WM, Giustini D, de Jonge GB, et al. De-duplication of database search results for systematic reviews in EndNote. Journal of the Medical Library Association. 2016; 104(3): 2403. PMid:27366130 https://doi .org/10.3163/1536-5050.10 4.3.014

[18] Pluye P, Gagnon MP, Griffiths F, et al. A scoring system for appraising mixed methods research, and concomitantly appraising qualitative, quantitative and mixed methods primary studies in Mixed Studies Reviews. International Journal of Nursing Studies. 2009; 46(4): 529-46. PMid:19233357 https://doi.org/10.1016/j . i jnurstu . 200 9.01 .009

[19] Pace R, Pluye P, Bartlett G, et al. Testing the reliability and efficiency of the pilot Mixed Methods Appraisal Tool (MMAT) for systematic mixed studies review. International Journal of Nursing Studies. 2012; 49(1): 47-53. PMid:21835406 https://doi.org/10.1016/j.ij nurstu.2011.07.002

[20] Pluye P, Robert E, Cargo M, et al. Proposal: A mixed methods appraisal tool for systematic mixed studies reviews [Internet]. 2011 [cited 2020 April 3]. Available from: http://mixedmethodsappr aisaltoolpublic.pbworks.com

[21] Miles MB, Huberman AM. Qualitative data analysis : an expanded sourcebook. Thousand Oaks, CA: Sage Publications; 1994.

[22] Langley A. Strategies for Theorizing from Process Data. The Academy of Management Review. 1999; 24(4): 691-710. https : //doi.org/10.5465/amr.1999.2553248

[23] Richer MC, Dawes M, Marchionni C. Bringing Knowledge to Action in the Context of a Major Organizational Transition. The Health Care Manager. 2013; 32(1): 4-12. PMid:23364412 https: //doi.org/10.1097/HCM.0b013e31827ed7ab

[24] Project Management Institute. A guide to the project management body of knowledge (PMBOK guide). 6th ed. Newtown Square, PA: Project Management Institute, Inc.; 2017.

[25] Lavoie-Tremblay M, Aubry M, Richer MC, et al. A Health Care Project Management Offices Strategies for Continual Change and Continuous Improvement. The Health Care Manager. 2018; 37(1): 4-10. PMid:28953067 https://doi .org/10.1097/HCM. 000000 0000000185

[26] Aubry M, Lavoie-Tremblay M. Rethinking Organizational Design for Managing Multiple Projects. International Journal of Project Management. 2018; 36(1): 12-26. https://doi.org/10.1016/j.ij proman.2017.05.012

[27] Lavoie-Tremblay M, Bonneville-Roussy A, Richer MC, et al. Project management office in health care: a key strategy to support evidencebased practice change. The Health Care Manager. 2012; 31(2): 15465. PMid:22534971 https://doi.org/10.1097/HCM. 0b013e31 82520676

[28] Klag M, Richer MC. The Case for Information Brokering During Major Change: The Experience of the Transition Support Office of the McGill University Health Centre. Healthcare Quarterly. 2016; 19(1): 17-23. PMid:27133603 https://doi .org/10.12927/hcq .2016 .24614

[29] Slosberg M, Nejati A, Evans J. Transitioning to a New Facility: The Crucial Role of Employee Engagement. J Healthc Manag. 2018; 63(1): 63-77. PMid:29303827 https://doi.org/10.1097/JH M-D-16-00019

[30] Bareil Cl, Savoie A, Meunier S. Patterns of Discomfort with Organizational Change. Journal of Change Management. 2007; 7(1): 13-24 https://doi.org/10.1080/14697010701232025

[31] Brownson RC, Colditz GA, Proctor EK. Dissemination and implementation research in health : translating science to practice. Oxford, NY: Oxford University Press; 2018. https ://doi.org/10.1093/ oso/9780190683214.001.0001

[32] Ulrich RS, Zimring C, Zhu X, et al. A review of the research literature on evidence-based healthcare design. HERD. 2008; 1(3): 61-125. PMid:21161908 https://doi.org/10.1177/19375867080010 0306

[33] Cameron E, Green M. Making sense of change management: a complete guide to the models, tools and techniques of organizational change. London, UK: Kogan Page Publishers; 2015. 
[34] Institute of Medicine. The future of nursing : leading change, advancing health. Washington, DC: Committee on the Robert Wood Johnson Foundation Initiative on the Future of Nursing, at the Institute of Medicine National Academies Press; 2011.

[35] Salmond SW, Echevarria M. Healthcare Transformation and Changing Roles for Nursing. Orthopaedic Nursing. 2017; 36(1): 12-25 PMid:28107295 https://doi.org/10.1097/NOR.0000000000 000308

[36] Sacco TL, Ciurzynski SM, Harvey ME, et al. Compassion Satisfaction and Compassion Fatigue Among Critical Care Nurses. Crit Care Nurse. 2015; 35(4): 32-44. PMid:26232800 https ://doi .org/10 $.4037 / \operatorname{ccn} 2015392$

[37] Marasovic C, Kenney C, Elliott D, et al. Attitudes of Australian nurses toward the implementation of a clinical information system. Comput Nurs. 1997; 15(2): 91-8.

[38] Chiocchio F, Beaulieu G, Boudrias JS, et al. The Project Involvement Index, psychological distress, and psychological well-being: Comparing workers from projectized and non-projectized organizations. International Journal of Project Management. 2010; 28(3): 201-11. https://doi.org/10.1016/j.ijproman.2009.05.007

[39] Packendorff J. The temporary society and its enemies: Projects from an individual perspective. In: Sahlin-Anderson K, Söderholm A, editors. Beyond project management: New perspectives on the temporary-permanent dilemma. Sweden: Cophenhagen Business School Press; 2002; 11-24.

[40] Johnson KJ, Bareil C. Quelles sont les pistes d'action face à une potentielle surcharge de changements dans le réseau de la santé? Montréal: PÔLE SANTÉ (HEC MONTRÉAL) [Internet]. 2016 [cited 2017 July 20]. Available from: http: //www.revuegestion.ca/informer/pistes-daction-fac e-apotentielle-surcharge-de-changements-reseau/
[41] Bernstrøm VH, Kjekshus LE. Effect of organisational change type and frequency on long-term sickness absence in hospitals. Journal of Nursing Management. 2015; 23(6): 813-22. PMid:24612363 https://doi.org/10.1111/jonm. 12218

[42] Brown H, Zijlstra F, Lyons E. The psychological effects of organizational restructuring on nurses. Journal of Advanced Nursing. 2006; 53(3): 344-57. PMid:16441540 https ://doi .org/10.111 $1 / j \cdot 1365-2648.2006 .03723 . x$

[43] Su SF, Boore J, Jenkins M, et al. Nurses' perceptions of environmental pressures in relation to their occupational stress. Journal of Clinical Nursing. 2009; 18(22): 3172-80. PMid:19538558 https://doi .org/10.1111/j.1365-2702.2008.02771.x

[44] Teo STT, Pick D, Newton CJ, et al. Organisational change stressors and nursing job satisfaction: the mediating effect of coping strategies. Journal of Nursing Management. 2013; 21(6): 878-87. PMid:23890099 https ://doi.org/10.1111/jonm. 12120

[45] Bourbonnais R, Brisson C, Malenfant R, et al. Health care restructuring, work environment, and health of nurses. American Journal of Industrial Medicine. 2005; 47(1): 54-64. PMid:15597361 https://doi.org/10.1002/ajim. 20104

[46] Lavoie-Tremblay M, Bonin JP, Lesage AD, et al. Contribution of the Psychosocial Work Environment to Psychological Distress Among Health Care Professionals Before and During a Major Organizational Change. The Health Care Manager. 2010; 29(4): 293-304. PMid:21045581 https://doi.org/10.1097/HCM.0b013e3181 $\mathrm{fa} 22 \mathrm{e}$

[47] Fridman M, Frederickson K. Oncology nurses and the experience of participation in an evidence-based practice project. Oncology Nursing Forum. 2014; 41(4): 382-8. PMid:24969248 https : //doi .or g/10.1188/14.0NF. 382-388 